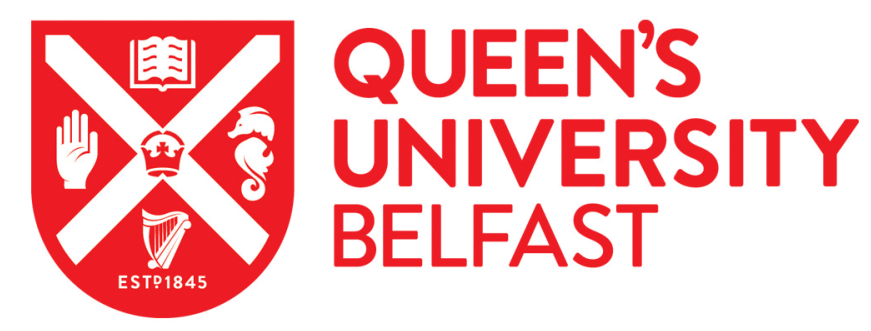

\title{
Working with Others: Reflections on Fieldwork in Postconflict Societies
}

Lawther, C., Killean, R., \& Dempster, L. (2019). Working with Others: Reflections on Fieldwork in Postconflict Societies. International Journal of Transitional Justice, 13(2), 387-397. https://doi.org/10.1093/ijt/ijz012

Published in:

International Journal of Transitional Justice

Document Version:

Peer reviewed version

Queen's University Belfast - Research Portal:

Link to publication record in Queen's University Belfast Research Portal

Publisher rights

( The Author(s) 2018. Published by Oxford University Press. All rights reserved. This work is made available online in accordance with the publisher's policies. Please refer to any applicable terms of use of the publisher.

\section{General rights}

Copyright for the publications made accessible via the Queen's University Belfast Research Portal is retained by the author(s) and / or other copyright owners and it is a condition of accessing these publications that users recognise and abide by the legal requirements associated with these rights.

Take down policy

The Research Portal is Queen's institutional repository that provides access to Queen's research output. Every effort has been made to ensure that content in the Research Portal does not infringe any person's rights, or applicable UK laws. If you discover content in the Research Portal that you believe breaches copyright or violates any law, please contact openaccess@qub.ac.uk. 


\section{Working with Others: Reflections on Fieldwork in Post-Conflict Societies}

\section{Introduction}

As the transitional justice field has expanded over the last two decades, so too has the drive to undertake research in conflict-affected and transitional societies. While there is a growing literature on challenging fieldwork, we are acutely aware that 'all too often researchers are left to their own innate sensibilities, talents and skills to identify and resolve a range of ethical, social and political challenges that inevitably arise in the field'. ${ }^{1}$ In the transitional justice context, those challenges include engagement with violence, human rights abuses and marginality, the instability of the settings and individual circumstances and the desire for assistance and advocacy. ${ }^{2}$

The authors of this field note are three early career researchers. This note takes as its starting point Darling's assertion that it is only through 'the practice of fieldwork' and 'critically thinking about the realities' of this practice that we can improve our ethicality and sensitivity in the field. ${ }^{3}$ In the following sections, we critically reflect on challenges encountered while undertaking sensitive fieldwork in post-conflict and transitional societies. As academics and researchers, we have been motivated by the 'transitional justice from below' perspective. Developed by Kieran McEvoy, intellectually, this concept draws on a number of fields (including political science, development studies and critical legal studies) which variously emphasise 'from below', 'grassroots' or legal-pluralist understandings of the intersection between politics, governance and law. ${ }^{4}$ In practice, it is founded on the reality that it is often those individuals and groups in post-conflict and post-authoritarian societies who have been on the receiving end of violence and human rights abuses who find that their voices are not heard or are marginalised as the transition takes shape and elite driven transitional justice processes are designed and implemented. Thus, one central problem for transitional justice is the emergence of 'transitional justice entrepreneurs' who reproduce or speak on behalf of victims. ${ }^{5}$ As researchers, we also select and reproduce participants' voices, and this note aims to critically reflect on how the power dynamics of transitional contexts influence and shape the practice of fieldwork.

This intellectual grounding of 'transitional justice from below' has influenced the trajectory and practice of our research from $\mathrm{PhD}$ onwards. Individually and collectively, we have been involved in a range of research projects involving fieldwork with victims, survivors and perpetrators of mass human rights violations. Those projects include an exploration of victim

\footnotetext{
1 John King, 'Demystifying field research', in Surviving Field Research: Working in violent and difficult situations, ed. Chandra Lekha Sriram, John King, Julie Mertus, Olga Martin and Johanna Herman (London: Routledge, 2009), 8. Other excellent sources of literature on this topic include: Carolyn Nordstrom and Antonius C.G. M. Robben, Fieldwork Under Fire: Contemporary Studies of Violence and Survival (California: University of California Press, 1995); Robert Burgess, Field Research: A Source Book and Field Manual (London: Allen and Unwin, 1982); Emma Pittaway, Linda Bartolomei and Richard Hugman, 'Stop Stealing Our Stories': The Ethics of Research with Vulnerable Groups', Journal of Human Rights Practice 2 (2) (2010), 229-251.

${ }^{2}$ Paul Gready, 'First Encounters: Early Career Researchers and Fieldwork', Journal of Human Rights Practice, 6 (2) (2014): 195-200.

3 Jonathan Darling, 'Emotions, Encounters and Expectations: The Uncertain Ethics of 'The Field', Journal of Human Rights Practice 6 (2) (2014): 201.

${ }^{4}$ Kieran McEvoy, 'Beyond Legalism: Towards a Thicker Understanding of Transitional Justice', Journal of Law and Society 34 (4) (2007): 411-440; Kieran McEvoy and Lorna McGregor, Transitional Justice from Below. Grassroots Activism and the Struggle for Change (Oxford: Bloomsbury, 2008).

5 Tshepo Madlingozi, 'On Transitional Justice Entrepreneurs and the Production of Victims', Journal of Human Rights Practice 2 (1) (2010): 208-228.
} 
participation in international criminal courts; analysis of post-conflict responses to 'disappearance'; an examination of the intersection between victim voice and agency and dealing with the past; a critical exploration of the representation of victims' voices at sites of 'dark tourism'; a study into the harm caused by attacks on cultural heritage; a comparative analysis of the role of non-state armed groups in contributing to reparation processes; and an exploration into the role of apologies in responding to past harms. ${ }^{6}$ Geographically, these projects span Nepal, Uganda, Guatemala, Peru, Colombia, Cambodia and Northern Ireland, ${ }^{7}$ and involve extensive qualitative fieldwork (semi-structured interviews, focus groups and site visits) and partnerships with local NGOs and victim and survivor groups.

Our combined experiences are brought to bear on this note. In the following sections we have identified a number of challenges associated with doing qualitative fieldwork in post-conflict contexts. These are explored within the three occasionally overlapping categories of practice, partners and positionality. In the conclusion we reflect on what we have learned from our experiences and make the case for a more reflexive approach to working with victims and survivors of gross human rights violations.

\section{Practice}

In this part of the paper we wish to hone in on the practice of doing research in the post-conflict context. We do not focus on research ethics or the practice of gaining institutional ethical approval. We are cognisant of the importance of 'doing no harm', guarding against retraumatisation and upholding the principles of confidentiality, privacy and informed consent. ${ }^{8}$ These ethical imperatives are rendered all the more acute by political polarization, the presence of armed actors, the hard won security of residents, the general unpredictability of events, and the traumatization of combatants and civilians in post-conflict contexts. ${ }^{9}$ Rather, our concern here is to focus on issues of empathy, expectation management and personal and professional practice when in the field.

Conducting sensitive fieldwork with often vulnerable individuals and communities demands a sensitivity to the challenges of empathy and expectation management. Empathy can of course facilitate the research process: helping interviewees feel at ease, lessening power imbalances between the researcher and the researched and facilitating the building of trust. However, empathy can inadvertently encourage the sharing of emotions that the researcher is not trained to deal with. We have each had experiences where interviewees have disclosed traumatic and upsetting experiences. In such circumstances, having a distress protocol and/or wellestablished relationships with local NGOs or statutory bodies who can provide advice and access to local support services has been invaluable. Expectation management requires similar sensitivity. Like other researchers, we have encountered many individuals who expressed hope that support would result from sharing their stories with researchers. ${ }^{10}$ Interviewees have requested legal and advocacy assistance, reparations or simply that their story be shared with the world. While such objectives will frequently fall outside one's research project or indeed,

\footnotetext{
6 Respective project identifiers are as follows: AH/N001451/1; DFEGCRF17-18 xx; AH/P006965/1; ES/N010825/1.

${ }^{7}$ Ethical approval for these studies was granted by the Ethics Committees of the xxx and xxx.

8 For the Economic and Social Research Council's Research Ethics Framework see: https://esrc.ukri.org/funding/guidance-for-applicants/research-ethics/

${ }^{9}$ Elisabeth Wood, 'The Ethical Challenges of Field Research in Conflict Zones', Qualitative Sociology, 29 (3) (2006): 373-386.

${ }^{10}$ Kate Cronin-Furman and Milli Lake, 'Ethics Abroad: Fieldwork in Fragile and Violent Contexts', PS: Political Science and Politics, 51 (3) (2018): 607-614.
} 
research capacity, we have learned to be alert to the possibility of over-promising or raising expectations. Commitments should be clear, modest and deliverable. ${ }^{11}$

Balancing professional objectives with the demands of highly sensitive fieldwork requires embedding preparatory and reflective practices in one's work, both prior to entering and when in the field. Like Darling, we would argue that encountering 'the field' cannot be siloed into distinct chunks of time but demands attentiveness to context and constant work to develop cultural sensitivity, political awareness and observational and listening skills. ${ }^{12} \mathrm{We}$ have found significant benefit from ensuring that such preparation precedes the fieldwork. As Dudai suggests, beyond academic articles and policy reports that form the staple preparation diet, researchers can sensitize themselves to local culture and concerns through local radio and newspapers, as well as novels and other creative media. ${ }^{13}$ When working with those affected by violent conflict, a close eye should be kept on the local political context. To do otherwise has implications for the personal safety of both researcher and respondent and may be interpreted as showing little respect for the context in which you are working. In our experience, political developments - peace processes, criminal trials or debates on truth recovery mechanisms can all influence participants' willingness to engage in research and their responses to our questions.

Once in the field, we have repeatedly encountered the importance of considering the use of language and phraseology during interviews. Language is often politically-loaded, for example the words 'terrorism', 'conflict' and 'war' in Northern Ireland, Israel/Palestine and a host of other post-conflict jurisdictions. The following extract from a Northern Ireland interview provides a case in point:

Interviewer: ...I think a lot of what we have seen, specifically in relation to the Troubles or the conflict here...

Michael: ... One of the issues is really, is the language that is often used. You said 'conflict'. To us, it is just pure terrorism... ${ }^{14}$

Such interactions raise the question of what we should do when the language we would use in our own lives, or in our academic work, is considered offensive by interviewees. In this regard, Hammersley and Atkinson advise that impressions that pose an obstacle to access must be avoided or countered as far as possible, while those which facilitate it must be encouraged, within the limits set by ethical considerations. ${ }^{15}$ However, this poses something of a contradiction in practice. Engaging in the impression management required to build rapport ${ }^{16}$ would suggest the interviewer should have avoided using the term 'conflict' as it had the potential to 'pose an obstacle.' Yet, good ethical practice requires the researcher to be to be 'as

\footnotetext{
${ }^{11}$ Gready, op cit n.2. We have, for example, found that the dissemination of short, accessible research briefs or the publication of articles in local newspapers an effective way of disseminating findings to those most closely affected by the research problem and a way to guard against the charge of Western researchers 'parachuting in' to collect data and 'parachuting out'.

12 Darling, op cit n.3.

${ }^{13}$ Dudai, personal correspondence, cited in Gready, op cit n.2.

${ }^{14}$ Excerpt from focus group conducted by one of the authors with survivors of the Northern Ireland conflict, May 2018.

${ }^{15}$ Martyn Hammersley and Paul Atkinson, Ethnography: Principles in Practice (London: Routledge, 2007$) 65$.

${ }^{16}$ Ibid.
} 
honest and ethical as possible'. ${ }^{17}$ While the interviewer's use of the term 'conflict' might be considered harmful, deliberately avoiding using the term could be considered a form of deception - especially if this is motivated by a desire to keep lines of communication open as part of 'an active construction of different researcher selves.' 18 These competing ethical considerations must be navigated in the field.

\section{Working with Partners}

While local knowledge on the part of the researcher is important, nuances around manners, customs, language and culture may remain invisible to even a well-prepared researcher. This issue becomes particularly pertinent in post-conflict contexts, ${ }^{19}$ where one is more likely to encounter vulnerable individuals and address sensitive topics. In such cases, identifying and partnering with a domestic organisation staffed by local people can be invaluable. Partners can counter potentially insensitive practices or lines of inquiry and inform researchers' knowledge of local contexts. ${ }^{20}$ However, one should not assume local partners will guarantee sensitivity and appropriate lines of inquiry. In practice, challenges can arise if local partners do not share the specific objectives of the researcher or if they have additional objectives in mind when conducting research. ${ }^{21}$ While this may not necessarily be malicious or indeed damaging to the partnership, it may lead to issues arising in the field. For example, partners may pursue different lines of questioning, which may include sensitive or potentially retraumatising topics excluded from the research instrument for ethical reasons. If language barriers exist between the researchers and research participants, this divergence may only emerge at a later stage of the project, raising issues around how researchers can assure their ethics committees that retraumatising topics will be avoided. Additional challenges can arise in ensuring partners are able, willing and aware of the need to inform researchers of local nuances and relevant information. Open and consistent communication is therefore crucial, while independent verification of relevant information may also provide a safeguard against misunderstandings. ${ }^{22}$

Having a local partner can also be invaluable in planning the logistics of fieldwork and facilitating access to research participants. By acting as gatekeepers, local partners can assist

\footnotetext{
17 Jeffrey A. Sluka, 'Reflections on Managing Danger in Fieldwork: Dangerous Anthropology in Belfast,' in Fieldwork Under Fire: Contemporary Studies of Violence and Survival, eds. Carolyn Nordstrom and Antonius C.G.M. Robben (Berkeley; London: University of California Press, 1995) 285. See also: Maurice Punch, 'Politics and Ethics in Qualitative Research,' in SAGE Handbook of Qualitative Research, eds. Norman K. Denzin and Yvonna S, Lincoln (USA: SAGE Publications Ltd, 1994) 83-97.

${ }^{18}$ Kathy, Hamilton, Susan Dunnett and Hilary Downey, 'Researcher identity: Exploring the transformatory power of the research experience', Journal of Consumer Behaviour, 11, (2012): 275-282.

19 Dyan Mazurana and Lacey Andrews Cale, 'Preparing for Research in Active Conflict Zones' in Research Methods in Conflict Settings, ed. Dyan Mazurana (Cambridge: Cambridge University Press, 2013) 277-292.

${ }^{20}$ Elisabeth Jean Wood, 'Reflections on the Challenges, Dilemmas and Rewards of Research in Conflict Zones', Research Methods in Conflict Settings, ed. Dyan Mazurana (Cambridge: Cambridge University Press, 2013), 301; Dyan Mazurana, Lacey Andrews Gale and Karen Jacobsen, 'A View from Below: Conducting Research in Conflict Zones' in Research Methods in Conflict Settings, ed. Dyan Mazurana (Cambridge: Cambridge University Press, 2013), 7.

${ }^{21}$ Ruth McAreavey and Chaitali Das, 'A Delicate Balancing Act: Negotiating with Gatekeepers for Ethical Research When Researching Minority Communities’ International Journal of Qualitative Methods, 12(1) (2013): $113-131,116$.

${ }^{22}$ For discussion of issues of veracity in interview, see e.g. Lee Ann Fujii 'Shades of Truth and Lies: Interpreting testimonies of war and violence,' Journal of Peace Research, 47 (2) (2010): 231-241; Robert W. White, “'I'm not too sure what I told you the last time": Methodological Notes on Accounts From High Risk Activists in the Irish Republican Movement', Mobilization, 12 (3) (2007): 287-306.
} 
in building trust with local communities, ${ }^{23}$ soothing misgivings that might arise from the arrival of foreign researchers. ${ }^{24}$ This becomes particularly important if the political situation within a state has become volatile, which may render participants more cautious or distrustful. By way of example, one project involved fieldwork during the lead up to an election, causing reluctance amongst participants to discuss anything they considered politically sensitive. The local partner played a valuable role in addressing those fears, and in establishing trust with participants. However, this may not always be the case. For example, participants may feel comfortable discussing research topics that are politically sensitive with international researchers, but not necessarily with locals. Indeed, researchers must be aware of the power dynamics at play in relation to the partner organisation's position within the state. ${ }^{25}$ They may have to balance certain dynamics that they do not necessarily wish to disclose, but which may influence their approach towards the research instrument, accessing participants, and outputs. Linked is the need to be aware that when researchers leave the field, their partners remain. This raises considerations for research participants, but also for the organisation. The 'do no harm' principle must also apply to the partner organisation. While it is not possible to guarantee no unintended consequences, ${ }^{26}$ researchers should avoid conducting research that may place the organisation or its staff at risk, giving such potential risks attention from the initial stages of project planning. ${ }^{27}$

The local partner's broader social, political or economic agendas may impact upon participant selection and access. ${ }^{28}$ Biases may emerge in selection of participants, for example gender norms or hierarchical cultures may negatively influence the diversity of the participant cohort. ${ }^{29}$ The risks associated with these forms of bias should be discussed with partner organisations before and during fieldwork, with any issues raised as soon as possible to allow time to address. In the case of one project, discussing concerns over a gender imbalance as it emerged allowed the project partner to take steps to address the issue while the research team remained in the field. Organisations may also prefer to choose participants with whom they have an existing relationship. While this approach has ethical benefits in that these individuals may be experienced in talking to researchers, such an approach may amplify the voices of 'repeat players' and compound the marginalisation of other, lesser-heard voices. ${ }^{30}$ Relying on existing relationships, particularly if the partner organisation has a history of collaborating with transitional justice scholars, may also lead to research fatigue amongst participants. ${ }^{31}$ This issue becomes heightened when researching victimised populations, who may be vulnerable, at risk of re-traumatisation, and have a variety of unmet needs and expectations. If individuals have repeatedly met researchers without visible benefit to themselves, the arrival of another group of researchers may be a source of frustration.

\footnotetext{
${ }^{23}$ Phyllis Eide and Carol B. Allen, 'Recruiting Transcultural Qualitative Research Participants: A Conceptual Model' International Journal of Qualitative Methods, 4(2) (2005): 44-56.

${ }^{24}$ Brendan Browne and Luke Moffett, 'Finding Your Feet in the Field: Critical Reflections of Early Career Researchers on Field Research in Transitional Societies', Journal of Human Rights Practice, 6 (2) (2014): 223237.

${ }^{25}$ McAreavey and Das, op cit n.21.

${ }^{26}$ Wood, op cit n.20 at 305.

${ }^{27}$ Molly Bingham and Steve Connors, 'Reporting the Story' in Research Methods in Conflict Settings, ed. Dyan Mazurana (Cambridge: Cambridge University Press, 2013), 169-220.

${ }^{28}$ Gurchathen S Sanghera and Suruchi Thapar-Bjorkert, 'Methodological Dilemmas: Gatekeepers and Positionality in Bradforf', Ethnic and Racial Studies, 31(3) (2008): 543-562.

29 Tricia Hynes, 'The issue of 'trust' or 'mistrust' in research with refugees: choices, caveats and considerations for researchers' UNHCR Evaluation and Policy Unit, Working Paper no. 98, 2003.

${ }^{30}$ Anthony Zwi et al., 'Placing ethics in the centre: Negotiating new spaces for ethical research in conflict situations' Global Public Health, 1(3) (2006): 264-277.

${ }^{31}$ Browne and Moffett, op cit n. 24.
} 
In cases where partners provide interpretation, they must also be considered an active 'coconstructor' of data. ${ }^{32}$ For Feldman, interviews are constructs, where knowledge is constructed between the interviewer and interviewee. ${ }^{33}$ When the interview involves a third party - in the form of an interpreter - they also contribute to this construction activity. Interviewees who do not speak the language of the interviewer become dependent on the interpreter to speak for them. ${ }^{34}$ To draw on Alcoff's seminal work, 'The Problem of Speaking for Others, ${ }^{35}$ the interpreter arguably plays the role of 'an advocate or a messenger,' speaking both 'about' and 'for' someone who cannot speak for themselves (or be understood by the listener without assistance). Alcoff warns that even when the act of 'speaking for' is 'authorized', the act of interpretation involves 'creating for them a self in the presence of others.' One specific manifestation of this created 'self' encountered during one period of fieldwork in Cambodia was the interpretation of several interviewee's accounts as including the self-descriptive phrase 'living document.' It was not clear whether interviewees were specifically using this phrase, or whether it was the term adopted by the interpreter. However, the partner organisation described encountering this notion when speaking to other survivors of the Khmer Rouge regime, and interviewees' explanations made clear that they meant something very similar: a keeper of memories about the past. The term is perhaps a useful example of this process of 'coconstruction': the partner's previous experience lent legibility to this term.

One final issue we wish to reflect on in relation to partners is the role of power dynamics within these relationships. Unequal power relations between researchers and local partner organisations may arise from differences in access to resources, capacity and knowledge, as well as divergences in world view, agendas or expectations. ${ }^{36}$ Inequalities may become more pronounced when engaging in partnerships between the Global North and Global South. While literature on such partnerships often focuses on donor-recipient relationships, this issue has become particularly live for UK-based researchers in light of schemes such as the Global Challenges Research Fund, which requires applicants to build 'strong and enduring partnerships' between academic communities in the UK and the Global South. Such relationships are intended to be based on a principle of mutuality, whereby both partners benefit from the partnership. Indeed, the ideal view of partnership is based on the concepts of reciprocity, trust and sharing different values, knowledges and practices. ${ }^{37}$ However, unequal power relations can impact on the pursuit of mutuality. ${ }^{38}$ For example, if money is being

\footnotetext{
${ }^{32}$ Bjork Bramberg and Karin Dahlberg, ' Interpreters in Cross-Cultural Interviews: A Three-Way Co-construction of Data', Qualitative Health Research, 23 (2) (2013): 241-247; Anna Chiumento, Atif Rahman, Laura Machin and Lucy Frith, 'Mediated research encounters: methodological considerations in cross-language qualitative interviews,' Qualitative Research, (2017) advance access: https://doi.org/10.1177/1468794117730121; Timothy Rapley, 'The art(fulness) of open-ended interviewing: some considerations on analysing interviews,' Qualitative Research 1 (3) (2001): 303-323.

${ }^{33}$ Alan Feldman, Formations of Violence: The Narrative of Body and Political Terror in Northern Ireland (Chicago; London: University of Chicago Press, 1991). See also: Deborah Court and Randa Abbas, 'Whose Interview Is It, Anyway? Methodological and Ethical Challenges of Insider-Outsider Research, Multiple Languages, and Dual-Researcher Cooperation,' Qualitative Inquiry, 19 (6) (2013): 480-488.

${ }^{34}$ Bogusia Temple and Alys Young, 'Qualitative Research and Translation Dilemmas', Qualitative Research, 4 (2) (2004): 161-178

${ }^{35}$ Linda Alcoff, 'The Problem of Speaking for Others' Cultural Critique, 20 (1991-1992): 5-32.

${ }^{36}$ Hazel Johnson and Gordon Wilson, 'North-South/South-North Partnerships: Closing the 'Mutuality Gap', Public Administration and Development, 26 (1) (2006): 71-80.

${ }^{37}$ Ibid at 73.

${ }^{38}$ John Harriss, 'Working Together: the Principles and Practice of Co-Operation and Partnership' in Managing Development. Understanding Inter-Organisational Relationships, eds. Dorcas Robinson, Tom Hewitt and John Harriss (London: Sage, 2000), 225-243.
} 
channelled through the academic institution, local partners may not feel they are able to challenge researchers' approaches or ideas without risking access to funding on which they may be relying. Such self-imposed restrictions can inhibit genuine and beneficial exchanges about the focus and methods of research. Differences in education may also create power imbalances: academics may carry assumptions about their expertise which create barriers to genuine partnership. This can be countered by researchers 'learning to learn', by valuing the 'different knowledges' brought by their partners, rather than seeking to always impart knowledge. ${ }^{39}$

\section{Positionality}

In this final section of the paper, we explore the position of a researcher in divided and postconflict societies. Rose has argued that positionality is never static, but rather is constituted in response to different audiences, demands and contexts throughout the research process. ${ }^{40}$ Our experiences reflect this reality, as explored below through the themes of subjectivity and power.

The authors support Adetoun's contention that a researcher should 'strive for impartiality and be unbiased in his or her analysis. ${ }^{41}$ In our experience and in those contexts where competing versions of the past overlap and compete, we consider it essential to remain open to and engaged with these diverse points of view. In practice this has meant being involved in research teams interviewing non-state armed actors, state forces, civilians on both sides of the political divide, NGO activists and others in quick succession. Maintaining professional neutrality and a primary concern with our core research questions on the impact and legacy of human rights violations has been essential to building trust and confidence amongst interviewees and support for the legitimacy of our work. ${ }^{42}$ It has also provided fulsome insights into the plurality of experience and the range of harms that accrue from violent conflict. ${ }^{43}$

However, we have also observed that maintaining neutrality can be challenging, particularly in a post-conflict society. The practice of fieldwork is inevitably mediated by one's own identity or the identity of the research team; as one commentator notes, 'most researchers in conflict settings acknowledge they are subjective and indeed that subjectivity affects their work'. ${ }^{44}$ For example, two of the authors have frequently had to mediate presumed assumptions regarding their own political background when doing sensitive field research in Northern Ireland. ${ }^{45}$ The practice of 'telling' - asking subtle questions as regards to an individual's background, where

\footnotetext{
${ }^{39}$ Johnson and Wilson, op cit n.36 at 79.

${ }^{40}$ Gillian Rose, 'Situating knowledges: positionality, reflexivity and other tactics', Progress in Human Geography, 21 (3) (1997): 305-320.

${ }^{41}$ Bolanle Adetoun, (2005), cited in Janine Clark 'Fieldwork and its Ethical Challenges: Reflections from Research in Bosnia', Human Rights Quarterly, 34 (3) (2012): 826

${ }^{42}$ Browne and Moffett op cit n.24.

${ }^{43}$ Cheryl Lawther, 'The Construction and Politicisation of Victimhood', in Victims of Terrorism: A Comparative and Interdisciplinary Study, eds. Orla Lynch and Javier Argomaniz (London: Routledge, 2014), 10-30.

${ }^{44}$ Pam Bell, 'The Ethics of Conducting Psychiatric Research in War-Torn Contexts', in Researching Violently Divided Societies: Ethical and Methodological Issues, eds. Marie Smyth and Gillian Robinson (London: Pluto, 2001), 184-192.

${ }^{45}$ See also Richard Reed, 'Researching Ulster Loyalism: The Methodological Challenges of the Divisive and Sensitive Subject’, Politics, 32 (3) (2012): 207-219.
} 
they live and the school they attended is well documented in Northern Ireland. ${ }^{46}$ As Joanne McEvoy points out, the mutual impact of identity between researcher and respondent matters because the data may vary from an interview where the respondent assumes the researcher is on their 'side', to one where the researcher is assumed to be from the opposing ethic group. ${ }^{47}$ For these authors, this has meant, for example, instinctively adopting the sort of multiplepersonality approach advocated by Thapar-Björkert and Henry, minimising the relevance of their assumed personal/political identity with when working with pro-state groups for fear of promoting over-identification with respondents while also being alive to the fact that such assumptions have opened doors and access to interviewees that might not otherwise have been possible. ${ }^{48}$ This approach is of course context dependent, as Sluka argues, 'In some cases, you might want to tell some people that you are neutral and others that you are not'. ${ }^{49}$

While we have acknowledged the power dynamics that can exist when working with a partner, we consider it important to also reflect on the dynamics that emerge between researchers and research subjects. Research with vulnerable communities can play an important role in amplifying the voices of those who may often find themselves marginalised in the aftermath of conflict. ${ }^{50}$ However, researchers should be cognisant of how they might be perceived, and of the relatively privileged position that they hold. These power dynamics can be amplified when moving between the Global North and Global South, where wealth disparities and access to education can create additional barriers between researchers and the communities in which they work.

This may manifest in a variety of ways. For example, participants may feel pressured to consent to the interview, or to respond to questions that make them feel uncomfortable. They may also give answers that they believe researchers expect or downplay the value of their own opinion. As a result, what we hear as researchers may not accurately represent participants' views. Participants may also find the terminology used by researchers unfamiliar or elitist, which can be distancing and inhibit the flow of communication. For example, two of the authors have been challenged on the academic use of the term 'actor', which the participant found insensitive in the context of conversations around victimhood. We have attempted to mitigate some of these risks within our previous projects. For example, by emphasising in consent forms and at the start of interviews that there are no right or wrong answers, and that the participants' views are vital contributions to the research. In relation to language, we have prioritised making language accessible, revisited research instruments in light of feedback, and sought the advice of local partners. While we acknowledge that it may be impossible to entirely mitigate the power dynamics that exist within fieldwork, we would argue that entrenching principles of humility and empathy can assist in mitigating their impact.

\section{Conclusion}

As we have argued in this note, being reflective about one's own behaviour, attitudes and approach towards participants and the practice of fieldwork is crucial. This is particularly the

\footnotetext{
${ }^{46}$ Alan Finlay, 'Reflexivity and the Dilemmas of Identification: An Ethnographic Encounter in Northern Ireland' in Researching Violently Divided Societies: Ethical and Methodological Issues, eds. Marie Smyth and Gillian Robinson (London: Pluto, 2001), 55-76.

47 Joanne McEvoy, 'Elite Interviewing in a Divided Society: Lessons from Northern Ireland', Politics, 26 (3) (2006): 184-191.

${ }^{48}$ Suruchi Thapar-Björkert and Marsha Henry, 'Reassessing the Research Relationship: Location, Position and Power in Fieldwork Accounts', International Journal of Social Research Methodology, 7 (5) (2004): 363-381.

${ }^{49}$ Sluka, op cit n.17.

${ }^{50}$ Clark, op cit at n. 42 .
} 
case that seek to pursue a 'from below' approach to their research. On the basis of our combined experience, we have found a number of key practices which we believe can contribute to a more rounded and sensitive field work experience for participants and researchers. These are to build your local knowledge; value - but seek to understand your local partners; and check your privilege. When entering the field, it is preferable that researchers have significant local knowledge themselves. Heightened awareness of the local context can allow research to be conducted and reported in a way that sensitively reflects local realities. Regardless of the degree of local knowledge, continuous critical analysis is a crucial aspect of managing relationships with partners, as is open and frank communication. Individual relationships can be extremely important in building positive partnerships,${ }^{51}$ and researchers should engage in what Johnson and Wilson have termed 'conscious agency', which focuses on establishing and maintaining trust and communication. ${ }^{52}$ To this end, the contributions of local partners should always be adequately credited. Finally, researchers should be constantly alive to power dynamics and should seek to any imbalances between themselves and the communities with which they work. With the increasing impetus towards in-situ fieldwork, it is essential that as scholars and practitioners we expand upon these conversations, provide adequate training to researchers who travel to work in these settings and that ethically problematic research is not rewarded.

\footnotetext{
${ }^{51}$ Sarah Lister, 'Power in Partnership? An Analysis of an NGO's Relationships with its Partners', Journal of International Development, 12 (2000): 227-239.

52 Johnson and Wilson, op cit n.36 at 79.
} 